\title{
Erratum to: The accuracy and timeliness of a Point Of Care lactate measurement in patients with Sepsis
}

\author{
Fatene Ismail ${ }^{1}$, William G. Mackay ${ }^{2}$, Andrew Kerry ${ }^{3}$, Harry Staines ${ }^{4}$ and Kevin D. Rooney ${ }^{1,5^{*}}$
}

\section{Erratum}

After publication of the original article [1], the authors noticed a mistake in Table 2. Patient numbers in lactate classification categories Low, Medium and High were incorrectly reported as forty one, seven and two respectively in the GEM 4000 column. The patient numbers that should have been reported in Table 2 are forty, three and seven. Table 2 appears in its correct form in this erratum.

Additionally, the incorrect patient numbers from Table 2 were reported in the 'Results' section. The 'Comparison of i-STAT against GEM premier 4000' sub-section should therefore have read as follows:

"Among the 50 samples (from 11 ICU patients) analysed on the GEM 4000 and the i-STAT; there were forty samples classified as low, three samples as medium and seven samples as high lactate risk level categories."

This mistake does not alter the validity of the results and conclusions as all lactate samples analysed on the i-STAT and GEM 4000 analysers fell in the same lactate risk categories.

\begin{abstract}
Author details
${ }^{1}$ Institute of Healthcare Policy and Practice, School of Health, Nursing and Midwifery, University of the West of Scotland, Paisley, UK. ${ }^{2}$ Institute of Healthcare Associated Infection, University of the West of Scotland and University Hospital Crosshouse, Kilmarnock, UK. ${ }^{3}$ Biochemistry Laboratory, Royal Alexandra Hospital, Paisley, UK. ${ }^{4}$ Sigma Statistical Services, Balmullo, UK. ${ }^{5}$ Intensive Care Unit, Royal Alexandra Hospital and Institute of Healthcare Policy and Practice, University of the West of Scotland, Paisley, UK.
\end{abstract}

Published online: 31 March 2016

\section{Reference \\ 1. Ismail F, Mackay WG, Kerry A, Staines H, Rooney KD. The accuracy and timeliness of a point of care lactate measurement in patients with Sepsis. Scand I Trauma Resusc Emerg Med. 2015;23:68. doi:10.1186/s13049-015-0151-x.}

* Correspondence: Kevin.Rooney@uws.ac.uk

${ }^{1}$ Institute of Healthcare Policy and Practice, School of Health, Nursing and Midwifery, University of the West of Scotland, Paisley, UK

${ }^{5}$ Intensive Care Unit, Royal Alexandra Hospital and Institute of Healthcare

Policy and Practice, University of the West of Scotland, Paisley, UK
Submit your next manuscript to BioMed Central and we will help you at every step:

- We accept pre-submission inquiries

- Our selector tool helps you to find the most relevant journal

- We provide round the clock customer support

- Convenient online submission

- Thorough peer review

- Inclusion in PubMed and all major indexing services

- Maximum visibility for your research

Submit your manuscript at

www.biomedcentral.com/submit
() Biomed Central 
Table 2 Lactate risk category classification determined by the i-STAT and the blood gas analysers

\begin{tabular}{llllll}
\hline Risk category & i-STAT & GEM 4000 & Risk category & i-STAT & OMNI S \\
\hline Low $<2.5 \mathrm{mmol} / \mathrm{L}(n=40)$ & 40 & 40 & Low $<2.5 \mathrm{mmol} / \mathrm{L}(n=45)$ & 45 & 45 \\
Medium $2.5-3.99 \mathrm{mmol} / \mathrm{L}(n=3)$ & 3 & 3 & Medium $2.5-3.99 \mathrm{mmol} / \mathrm{L}(n=2)$ & 2 & 2 \\
High $\geq 4 \mathrm{mmol} / \mathrm{L}(n=7)$ & 7 & 7 & High $\geq 4 \mathrm{mmol} / \mathrm{L}(n=0)$ & 0 & 0
\end{tabular}

The above table shows that all lactate samples (50) analysed on the i-STAT and the GEM 4000 analysers fell in the same lactate risk level categories Similarly, all lactate samples (47) analysed on the i-STAT and the OMNI S fell in the same lactate risk level categories 